\title{
Salud mental en el trabajo: entre el sufrimiento en el trabajo y la organización saludable
}

\author{
Mental health at work: between suffering at work and healthy \\ organization
}

\begin{abstract}
Saúde mental no trabalho: entre o sofrimento no trabalho e organização saudável
\end{abstract}

\author{
María Alejandra Gómez Vélez \\ Paola Andrea Calderón Carrascal ${ }^{2}$
}

\section{Resumen}

Recibido: 27.01.2017 - Arbitrado: 22.02.2017 - Aprobado: 13.03.2017

El presente artículo plantea una revisión de documentos que posibilitó una reflexión acerca del estado de la salud mental en el escenario laboral colombiano, con el objetivo de visibilizar la construcción de organizaciones proclives a la salud laboral y al bienestar. Esta revisión nace de aportar a la investigación "Prácticas profesionales en la educación superior de algunas ciencias sociales: preparación para el acceso y condiciones de la vida laboral en el siglo XXI". Como resultados de la revisión, se encontró que Colombia cuenta con una legislación que busca mejorar y crear escenarios de autocuidado, prevención, promoción de la salud y asistencia a los accidentes y enfermedades laborales; velando por unas condiciones de trabajo más idóneas y de atención interdisciplinaria. No obstante para lograrlo, se requiere un cambio en las formas de relación en el ámbito laboral y en el aumento de la valoración de la relación de interdependencia que se da en grupos de trabajo, para ello urge también mayor sensibilización y pedagogía. De igual forma, se encontró que además de la legislación que se genera en el escenario mundial, del cual Colombia hace parte, se presentan dos propuestas epistemológicas que, desde el escenario de las necesidades psicosociales en el trabajo, explican la urgencia de entender y afrontar, lo que sucede en las organizaciones. Una de ellas es una perspectiva psicodinámica, que indaga por el sufrimiento que se genera en el trabajo en el escenario actual, con el objetivo de visibilizar y desnaturalizar las prácticas cotidianas que cosifican a las personas y les restan posibilidades de realización. Y la otra, es la propuesta de organización saludable, que se respalda en la psicología positiva, y se denomina Psicología Ocupacional u Organización Positiva (PoP), que considera la salud del empleado como un objetivo legítimo que debe incluirse en todas las políticas organizacionales, para beneficio tanto de los empleados como de la organización.

Palabras clave: bienestar, calidad de vida laboral, sufrimiento, factor de riesgo psicosocial.

\footnotetext{
${ }^{1}$ Psicóloga de la Universidad de Antioquia, Especialista en Psicología Organizacional de la universidad San Buena Aventura; Magister en Ciencias Sociales de la Universidad de Antioquia, Candidata a Doctora en Psicología de la Pontificia Universidad Católica de Argentina; Docente e investigadora de la Facultad de Psicología de la Universidad Pontificia Bolivariana. Mail: alejandra.gomez@upb.edu.co

${ }^{2}$ Psicóloga de la Universidad Católica Luis Amigó, Especialista en Psicología Clínica y Salud Mental de la Universidad Pontificia Bolivariana; estudiante de Maestría en Psicoterapia de la Universidad Pontificia Bolivariana, Docente de cátedra de la Facultad de Psicología y Trabajo Social de la Universidad Pontificia Bolivariana. Mail: paola.calderon@upb.edu.co

Citación del artículo: Gómez, M., Calderón, P. (2017). Salud mental en el trabajo: entre el sufrimiento en el trabajo y la organización saludable. Revista Katharsis, N 23, enero-julio 2017, pp.177-201, Disponible en http://revistas.iue.edu.co/index.php/katharsis
} 


\begin{abstract}
The article subject is the status of mental health of the Colombian worker and it is the outcome of a review of papers focusing on the building of organizations that encourage the occupational health and employees' wellness. The purpose of this review is to contribute to the research "Professional practices in higher education of some social sciences: preparation and conditions to access the working life in the twenty-first century." As a result of the review, it was found that Colombia has legislation that seeks to improve and create conditions of self-care, prevention, health promotion and assistance to employees who suffered occupational accidents and diseases; ensuring a better working conditions and interdisciplinary attention. However, in order to achieve this, it has been necessary to change the types of relationship in the workplace and increase the value of the interdependence that occurs in working groups. It also requires greater awareness and pedagogy. In addition, it was found that, on top of the legislation that is generated in world forums, of which Colombia is part, two epistemological proposals are presented based on the psychosocial needs at work, explaining the urgency to understand and act towards what happens in organizations: One of them is a psychodynamic perspective, which investigates the suffering that is generated at work, aiming to make it visible and to denaturalize the daily practices that make people just objects and keep them off personal realization. The other one is the proposal of a healthy organization, supported by positive psychology, and it is called Occupational Psychology or Positive Organization (PoP). It considers employee health as a legitimate purpose that must be included in all organizational policies, for the benefit of both, the employees and the organization.
\end{abstract}

Key words: welfare, quality of working life, suffering, psychosocial risk factor.

\title{
Resumo
}

Este artigo apresenta uma análise dos documentos que permitiram uma reflexão sobre o estado de saúde mental no cenário de trabalho colombiano, com o propósito de fazer visível a construção de organizações que tendam à saúde e ao bem-estar no trabalho. Esta revisão resulta da pesquisa "práticas profissionais no ensino superior de algumas ciências sociais: preparação para o acesso e as condições de vida no trabalho no século XXI". Como resultados constatou-se que a Colômbia tem uma legislação que procura melhorar e criar cenários de auto-cuidado, prevenção, promoção da saúde e assistência a acidentes e doenças geradas pelo trabalho; velando pelas condições de trabalho melhores e com atenção interdisciplinar. No entanto, para alcançar este propósito, é preciso mudar as formas de relacionamento no trabalho e no aumento da valorização da relação de interdependência que ocorre em grupos de trabalho; por isso também é preciso uma maior sensibilização e educação. Da mesma forma, verificou-se que além da legislação que é gerada no cenário mundial, da qual a Colômbia faz parte, duas propostas epistemológicas as quais desde as necessidades psicossociais no trabalho, explicam a urgência de compreender e lidar com o que acontece nas organizações. Uma delas é uma perspectiva psicodinâmica que explora o sofrimento gerado no trabalho no cenário atual, com o objectivo de tornar visível e desnaturar as práticas cotidianas que voltam objetos as pessoas e diminuem as suas posibilidades de realização. E a outra é a proposta de organização saudável, que é suportada pela psicologia positiva, e é chamada Psicologia Ocupacional ou Organização positiva

Citación del artículo: Gómez, M., Calderón, P. (2017). Salud mental en el trabajo: entre el sufrimiento en el trabajo y la organización saludable. Revista Katharsis, N 23, enero-julio 2017, pp.177-201, Disponible en http://revistas.iue.edu.co/index.php/katharsis 
(PoP), que considera a saúde do trabalhador como um objectivo legítimo a ser incluído em todas as políticas organizacionais, para o benefício dos empregados e da organização.

Palavras-chave: bem-estar, qualidade de vida no trabalho, sofrimento, fator de risco psicossocial.

\section{Introducción}

Como profesionales de la salud mental, comprometidos con el ejercicio aplicado de la psicología, nos surgen inquietudes en torno a un tema que ha trascendido a través de medios de comunicación, en diferentes publicaciones internacionales, nacionales y locales, orientadas a comprender como es afectada la salud mental en el trabajo. Esta cuestión, si bien no es nueva, se ha convertido en un tema de actualidad porque hay más conciencia y mayor interés por disminuir los efectos adversos del trabajo y exige, a su vez, mayor atención y compromiso de las organizaciones, del Estado y de los trabajadores, partiendo del actual escenario de competitividad que presiona por resultados de forma apremiante.

Algunos medios de comunicación como revistas exponen algunos datos que podemos citar a continuación:

Diferentes estudios realizados por la Organización Internacional del Trabajo (OIT), la Organización Mundial de la Salud (OMS) y entidades particulares evidencian una gran preocupación por el aumento del estrés laboral. Se calcula que más del $30 \%$ de la población mundial padece este mal, incluso en países industrializados la cifra alcanza niveles superiores. En América Latina, las estadísticas mencionan que cerca del $40 \%$ de los trabajadores ha tenido estrés en México, Argentina, Chile y Colombia. (elempleo, 24 de marzo de 2015, párr. 1).

Los más de 20 suicidios registrados entre empleados de France Telecom desde el pasado mes de febrero han hecho saltar todas las alarmas en el país galo, que ha empezado a mirar de reojo la salud mental de sus trabajadores. ¿Podrían vivirse situaciones similares en nuestro país? ¿Puede un trabajo estresante conducir por sí solo a tomar esa decisión? (Valerio, M. 15 de octubre de 2009, párr. 1).

Los japoneses han denominado Karoshi a las muertes producto directo del estrés laboral, personas que trabajan más de 65 horas semanales y mueren producto de un accidente cardíaco, cardiovascular o cerebro vascular, entran dentro de esta categoría de defunción producto de no aportarle descanso al cuerpo y la mente. (Salud.com.ar., 3 de agosto de 2015, párr. 1).

La OMS (2016) dice que la salud mental es un componente integral y esencial de la salud, y sobre la salud señala que es un estado de bienestar físico, mental y social, y no simplemente la ausencia de afecciones o enfermedades. Es así como presume que la salud mental es algo más que la ausencia de trastornos o imposibilidades mentales.

Se entiende a la salud mental como un estado de bienestar en el que la persona es capaz de hacer frente al estrés habitual de la vida, es capaz de trabajar y de contribuir a su

Citación del artículo: Gómez, M., Calderón, P. (2017). Salud mental en el trabajo: entre el sufrimiento en el trabajo y la organización saludable. Revista Katharsis, N 23, enero-julio 2017, pp.177-201, Disponible en http://revistas.iue.edu.co/index.php/katharsis 
comunidad. En este sentido, la salud mental es el cimiento del bienestar individual y del funcionamiento conveniente de la comunidad.

La salud mental y el bienestar son fundamentales para nuestra capacidad colectiva e individual de pensar, manifestar sentimientos, interactuar con los demás, ganar el sustento y disfrutar de la vida. Sobre esta base se puede considerar que la promoción, la protección y el restablecimiento de la salud mental son preocupaciones vitales de las personas, las comunidades y las sociedades de todo el mundo (párr.3).

Acosta et al., (2006) señalan que, en las últimas décadas, las formas de trabajo que responden a nuevas formas de organización del trabajo y producción han ido despersonalizando la relación con el trabajador y dan como ejemplo las maneras en que se dividen las tareas que imposibilitan la realización del ser humano en su trabajo.

Para Andrés et al., (2015), en la sociedad se ha comenzado a apreciar los efectos adversos que tienen sobre la salud los riesgos psicosociales. Señalan los autores que han sido los medios de comunicación los que presentan casos de acoso laboral o psicológico, síndrome de burnout en el trabajo, muertes por presión que comprometen el sistema cardiovascular, ansiedad, etc. Agregan, que se ha comenzado a visualizar las prácticas organizacionales de la gestión laboral que "[...] exigen disponibilidad absoluta en todos los ámbitos de la relación laboral (horarios, tareas)" (p. 15), lo que precarizan las relaciones y las condiciones de trabajo, incluso con sobrecarga.

Se entiende que la salud laboral (ISTAS, s.f.) se construye con condiciones equilibradas, en un ambiente conveniente, en el que las personas que trabajan puedan realizar su actividad con dignidad y en las que puedan participar para la mejora de las condiciones de salud y de seguridad.

Houtman \& Kompier (1998), definen a la salud mental como un estado de bienestar psicológico y social del individuo en un entorno sociocultural dado, facilitando estados de ánimo y afectos positivos, como, por ejemplo: placer, satisfacción y comodidad; o negativos como: ansiedad, estado de ánimo depresivo e insatisfacción. De igual forma, se refieren a la salud mental como proceso, cuando se dan conductas de afrontamiento, es decir, cuando la persona lucha, se esfuerza e insiste por conseguir independencia y autonomía. La salud mental puede asociarse también a características de la persona, es decir, competencias para resolver de forma eficaz las circunstancias de la vida cotidiana, para tener un adecuado dominio del entorno, en otras palabras, ser autoeficaz. Además, una persona mentalmente sana, que se muestra interesada por su entorno, participa en actividades motivadoras y busca su propia proyección por medios personalmente significativos.

Señalan Vásquez y Hervás (2008) y Gimeno (2012), que la salud mental es más que la ausencia de trastornos mentales, explican que la salud mental vista desde una óptica positiva conlleva un estado emocional positivo, y un modo de pensar más considerado sobre sí mismo y los demás, en el que se puede tener unas expectativas de un futuro positivo y más adaptativo para interpretar la realidad. De alguna manera, se trata de tener una perspectiva que se enfoque más en la posibilidad que en la limitación misma con la que se pueda contar. Supone que los seres humanos también pueden disponer de recursos para afrontar las adversidades y que, incluso, puedan lograr desarrollarse.

Citación del artículo: Gómez, M., Calderón, P. (2017). Salud mental en el trabajo: entre el sufrimiento en el trabajo y la organización saludable. Revista Katharsis, N 23, enero-julio 2017, pp.177-201, Disponible en http://revistas.iue.edu.co/index.php/katharsis 
Para la OMS (2016), la salud mental se determina por factores sociales, psicológicos y biológicos. Es así como las presiones socioeconómicas constantes crean un riesgo para la salud mental de las personas y comunidades. Indicadores de este riesgo son, por ejemplo, la pobreza y el bajo nivel educativo. De igual manera, la OMS (2016) relaciona una "mala salud mental" con cambios sociales rápidos, discriminación de género, exclusión social, condiciones de trabajo estresantes, violencia, mala salud física y violaciones a los derechos humanos.

Brundtland, 2000, (citado por Prieto Rodríguez, 2002) señala que hay tres aspectos que determinan las condiciones de la salud mental. Primero, el relacionado con la velocidad del mundo actual, porque produce cambios en la vida de las personas en las dimensiones cultural, laboral y tecnológica, y también en el desarrollo mundial con la urbanización, el crecimiento rápido de la economía y la degradación del medio ambiente. Segundo, el relacionado con la pobreza, porque es un limitante fundamental para lograr bienestar mental. Y tercero, el proceso de envejecimiento, el cual se ha identificado a nivel mundial, fundamentalmente en países desarrollados, como un problema invariable.

Es importante observar un modelo de salud mental en el trabajo, que brindan Houtman \& Kompier (1998), para mostrar la relación sistémica entre el entorno laboral, las características de la persona que trabaja y los trastornos de salud mental a largo plazo (Ver figura 1).

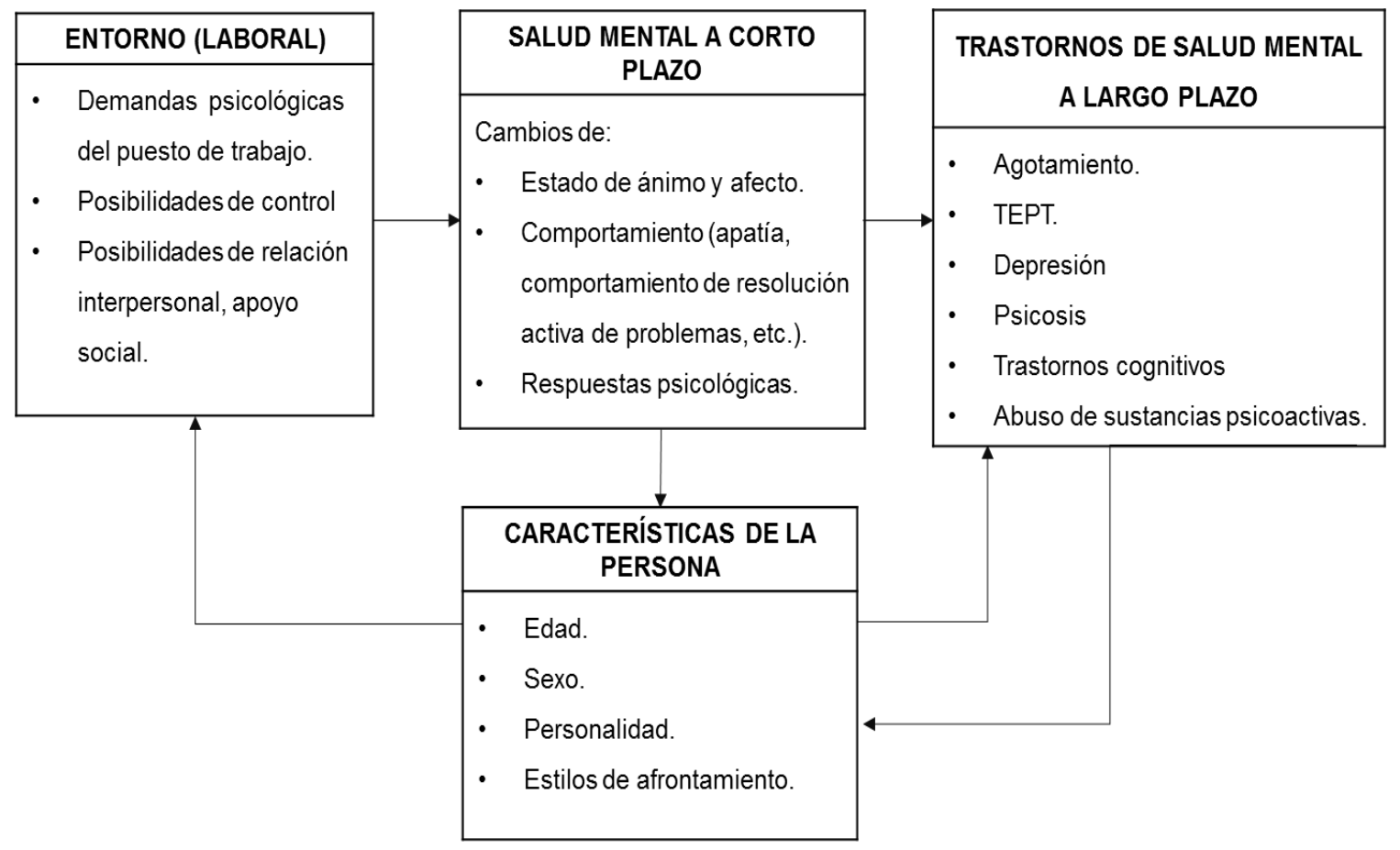

Figura 1. Modelo de Salud Mental en el contexto laboral. Tomado de Houtman \& Kompier (1998, p.2).

La relación sistémica y de interdependencia que existe entre los elementos que componen a la organización, son clave para comprenderla e intervenirla como una unidad social susceptible de mejoramiento y de logro de mayor bienestar y salud.

Citación del artículo: Gómez, M., Calderón, P. (2017). Salud mental en el trabajo: entre el sufrimiento en el trabajo y la organización saludable. Revista Katharsis, N 23, enero-julio 2017, pp.177-201, Disponible en $\mathrm{http}: / /$ revistas.iue.edu.co/index.php/katharsis 
Para Pando et al. (2006) el estudio de la salud mental en el ámbito laboral, entendido como un problema de salud pública, amerita una forma de entender la salud que no se reduzca a indicadores negativos, de riesgos de trabajo como la morbi-mortalidad.

Pando et al. (2006) señalan que autores que contribuyen con una concepción positiva de la salud son Marie Jahoda, Gordon Allport, y Strupp y Hadley. Igualmente, estos autores proponen un concepto sobre la salud mental para el ámbito laboral, a partir de la revisión del concepto de salud de estos autores, y plantean que la salud mental puede ser entendida como un proceso dialéctico del comportamiento humano individual y colectivo, al ser una práctica social, que se basa y representa la capacidad de transformación de la realidad en el proceso de producción, a través del sistema socioeconómico dominante en el momento.

Esta concepción permite ver al ser humano en una serie de logros y desarrollos, que no se refieren a una psicopatología, pero si una capacidad de la salud mental. Muestra de esta capacidad "[...] podrían ser la conciencia social, capacidad de transformar la realidad, la autoestima, el proyecto de vida, la creatividad, la grupalidad y redes sociales, la capacidad para dar y recibir afecto, etc." (p. 85).

Para Dejours (2010) la pérdida de la salud mental en el escenario de trabajo se ha relacionado con la evolución de la organización del trabajo y con la entrada de nuevas técnicas como la evaluación individual del desempeño, la "calidad total", la subcontratación y el uso progresivo de trabajadores independientes. Dejours (2010) enfatiza que esto ha incrementado la presión productiva, el aislamiento y la soledad. Así mismo como las patologías mentales que resultan de una fragilización de los vínculos entre las personas "[...] y que, en lugar de la confianza, la lealtad y la solidaridad, instalan en el mundo laboral el individualismo, la deslealtad y al fin de cuentas, una implacable soledad en medio de la masa" (párr. 10).

Dejours (2010) señala cinco categorías en torno a las patologías mentales que se presentan en el escenario actual: i. Las patologías de sobrecarga, como el síndrome de burnout, el karoshi y los problemas músculo-esqueléticos; ii. Las patologías que complican las agresiones cuya víctima es el trabajador; iii. Las patologías de personas que son privadas de empleo o que son despedidas, y que dan paso al aumento de depresiones, alcoholismo y otras formas de toxicomanías, y el aumento de la violencia; iv. Las patologías del acoso laboral o psicológico; y v. Las patologías depresivas, que pueden llegar hasta el intento de suicidio y los suicidios.

\section{Sobre los riesgos psicosociales laborales en el escenario actual}

Los rápidos cambios en el mundo laboral y en la fuerza de trabajo, según manifiestan algunos autores, implican unos nuevos riesgos, entre los cuales aparece el estrés, por ello es importante tener en cuenta las características y demandas del trabajo en los tiempos modernos (Hurrel, Murphy, Sauter \& Levi, 1998).

Señala Morales (2016) que los riesgos laborales cambian continuamente a razón de la evolución que se da a partir de los cambios científicos y tecnológicos, de políticas económicas y administrativas, la introducción de nuevas técnicas en los procesos productivos, a la innovación administrativa en las condiciones de trabajo.

Citación del artículo: Gómez, M., Calderón, P. (2017). Salud mental en el trabajo: entre el sufrimiento en el trabajo y la organización saludable. Revista Katharsis, N 23, enero-julio 2017, pp.177-201, Disponible en http://revistas.iue.edu.co/index.php/katharsis 
Y estos cambios también han traído (Gómez, 2007), unas nuevas realidades relativas a la desaparición y fusiones de empresas, lo que ha dado lugar a la perdida de estabilidad, a una mayor incertidumbre, a una pérdida de control y una continua necesidad de replantear los proyectos de vida familiares y personales.

Cabe decir que el trabajo, es una actividad de importancia para todas las personas, como bien dice Torres (2016), dado que es fuente de ingreso económico y sostenimiento, pero, además, puede ser tanto fuente de satisfacciones, como de desgaste y de diversos conflictos. Igualmente, el trabajo es uno de los ámbitos, donde las personas permanecen una cantidad importante de tiempo y en la que entran en contacto con un gran número de factores de riesgo, de acuerdo a la actividad laboral que desarrollan (Nava, 2016).

Es así, que la salud laboral surge como una respuesta al conflicto que se produce entre la salud y las condiciones de trabajo, y busca hacer control e intervención sobre las condiciones de trabajo y la salud de los trabajadores (Andrade \& Gómez, 2008).

Según lo expresa una noticia del Banco Mundial (2016), los problemas de salud mental producen muertes en nuestras sociedades a nivel mundial. En el caso de la depresión que aqueja a 350 millones de personas y es la principal causa de discapacidad a nivel mundial. Constituyendo una gran carga social, los trastornos mentales siguen siendo parte de la penumbra, por la huella, los prejuicios y el miedo. Intervenir esta situación ha llegado a ser más urgente que nunca, esto también teniendo presente la migración forzada y los conflictos constantes que se observan en el mundo. Por eso el Grupo Banco Mundial y la Organización Mundial de la Salud (OMS) apoyan todos los esfuerzos para enfrentar este tema de los trastornos mentales, ubicándolo en un lugar central del programa mundial de desarrollo y han realizado un evento, el cual tuvo como objetivo que los ministros de finanzas, las instituciones multilaterales y bilaterales, la comunidad empresarial, los innovadores del área tecnológica, y la sociedad civil participasen en las inversiones que se necesitan en salud mental y apoyo psicosocial, y en los rendimientos previstos en términos de beneficios de salud, sociales y económicos.

Un sondeo de opinión realizado por la EU-OSHA en Europa, muestra que alrededor de la mitad de los trabajadores consideran que es frecuente el problema del estrés en el escenario de trabajo. Y entre las causas con las que más lo relacionan son la reorganización en el trabajo, la inseguridad en el puesto de trabajo, muchas horas de trabajo, el acoso y la violencia en el trabajo (Agencia Europea para la Seguridad y Salud en el trabajo, 2016).

Con relación al escenario laboral, la salud vista desde la perspectiva psicosocial, urge más atención, conciencia social, visión a mediano y largo plazo, y pedagogía, además de hacerlo por las personas también por la continuidad de las organizaciones:

Sánchez (2006) afirma, con base en un estudio realizado por la OIT titulado "Mental health in the workplace", que el trabajo paulatinamente se ha ido convirtiendo en un "foco generador de cuadros neuróticos y sus derivados" (p.66). Igualmente comenta que la principal investigadora de dicho estudio, Phyllis Gabriel, explica que "los empleados sufren desánimo, cansancio, ansiedad, estrés, pérdida de ingresos e incluso desempleo, con el agravante, en algunos casos, del inevitable estigma que lleva asociado la enfermedad mental" (p.66). Y que, además, para los empleadores "los costos se traducen en baja productividad, disminución de los beneficios, altas tasas de rotación y mayores costos de

Citación del artículo: Gómez, M., Calderón, P. (2017). Salud mental en el trabajo: entre el sufrimiento en el trabajo y la organización saludable. Revista Katharsis, N 23, enero-julio 2017, pp.177-201, Disponible en http://revistas.iue.edu.co/index.php/katharsis 
selección y formación del personal sustituto". Para completar el escenario subraya que "Para los gobiernos, los costos incluyen gastos de atención sanitaria, pagos por seguros y merma de renta a nivel nacional" (p. 66). Es un escenario en el que todos pierden en el mediano y largo plazo (Sanchez, 2006; OIT, 2000).

Para la Agencia Europea para la Seguridad y Salud en el trabajo (2016), los riesgos psicosociales y el estrés laboral afectan de forma significativa la salud de las personas, de las organizaciones así como las economías nacionales. Según los datos de esta agencia, la mitad de los trabajadores europeos opinan que el estrés es común en sus lugares de trabajo y que el estrés suele interpretarse mal y estigmatizarse. Agregan que los riesgos psicosociales proceden de deficiencias en el diseño y gestión de la organización, sumado a un pobre contexto social del trabajo, en el que se producen como resultados psicológicos, físicos y sociales negativos, el estrés laboral, el agotamiento y la depresión. Plantean como condiciones de trabajo que contienen riesgos psicosociales: cargas de trabajo excesivas; exigencias contradictorias y falta de claridad de las funciones del puesto; falta de participación en la toma de decisiones que afectan al trabajador y falta de influencia en el modo en que se lleva a cabo el trabajo; gestión deficiente de los cambios organizativos, inseguridad en el empleo; comunicación ineficaz, falta de apoyo por parte de la dirección o los compañeros; acoso psicológico y sexual, violencia ejercida por terceros.

Para Villalobos (2004), la importancia que tienen las enfermedades que son causadas por el estrés en el trabajo no se ha visto de forma contundentemente expresada en el desarrollo de la legislación de los países, y ejemplifica con los países de la Unión Europea y de Estados Unidos, en los que si bien se aprecia un mayor reconocimiento a los casos de acoso laboral, burnout, enfermedades mentales y cardiovasculares, el reconocimiento frecuentemente se hace después de que los trabajadores interponen un proceso judicial y demuestran con evidencias las condiciones de trabajo estresantes.

Señala Martínez (2016), que el estrés que se produce en el escenario laboral es una de las fuentes generadoras de riesgos psicosociales. Es interesante reflexionar y recordar que si bien el estrés es una respuesta a unas condiciones, a su vez, propicia un escenario que favorece un deterioro de la salud y del ambiente de trabajo.

Barlow (2000), presenta unas fuentes de estrés laboral que exponen a las personas a exigencias cotidianas que pueden afectar la salud mental y su bienestar (ver tabla 1).

Tabla 1

Fuentes de estrés laboral y de carrera

\begin{tabular}{ll}
\hline \multicolumn{2}{c}{ Creadores de estrés laboral y de carrera } \\
\hline - Plazos límite & - Líneas de autoridad confusas \\
- Dificultades de comunicación & - Abuso o maltrato verbal \\
- Clientes hostiles & - Falta de desafíos en el trabajo \\
- Directivas con grandes expectativas & - Fracasos personales \\
- Cosas que hacen perder el tiempo & - Compañeros de trabajo que fuman \\
- Salarios demasiado bajos & - Exceso de ruido en el entorno de trabajo \\
- Problemas de desarrollo de su carrera & - Impresos sin sentido \\
- Falta de aprecio del trabajo & - Gestión de crisis \\
- Aburrimiento & - Falta de privacidad en el trabajo \\
\hline
\end{tabular}

Citación del artículo: Gómez, M., Calderón, P. (2017). Salud mental en el trabajo: entre el sufrimiento en el trabajo y la organización saludable. Revista Katharsis, N 23, enero-julio 2017, pp.177-201, Disponible en http://revistas.iue.edu.co/index.php/katharsis 
- Cambios administrativos

- Traslados de ida y vuelta del trabajo

- Tener responsabilidades sin tener el control

- Colegas incompetentes

- Demasiadas reuniones

- Interrupciones

- Trabajo que nunca se acaba

- Inseguridad laboral

- Entorno físico de trabajo

- "El cliente siempre tiene la razón"

- Evaluación de la situación

- Quejas crónicas de los clientes

- Moral baja

Nota: Adaptado de Barlow (2000, p. 60).
- Políticas de oficina

- Ser nuevo en el trabajo

- Trabajo nocturno

- Sustituir a compañeros de trabajo enfermos

- Falta de apoyo del jefe

- Público exigente

- Uniformes incómodos

- Falta de entrenamiento en el trabajo

- Fallos en la maquinaria y equipos

- Acoso sexual en el trabajo

- Conflictos entre el personal

- Gente que llega tarde al trabajo

- Problemas poco claros

\section{Los cambios que se vienen dando en la legislación colombiana.}

Además de la pobreza y el bajo nivel educativo, señalados por la OMS (2016), las condiciones de trabajo que exponen a las personas a factores de riesgo laboral contribuyen a poner en la cuerda floja la salud biopsicosocial de las personas que trabajan. Hay datos de interés que nos ubican frente a las dificultades de salud en general que se encuentran en el escenario laboral colombiano:

En Colombia la situación no es nada deseable en materia de prevención de riesgos de accidentes y enfermedades laborales. 2015 ha sido el año con mayor reporte de accidentes laborales, con un total de 723.836. Lo que quiere decir que cada hora se presentan 244 accidentes de trabajo. Y en cuanto a fallecimientos, cada día en promedio mueren 2 personas por causas de accidentes laborales (Escuela Nacional Sindical, 2016, p. 2).

La accidentalidad, siniestralidad y las enfermedades laborales plantean un escenario ya preocupante. La salud mental laboral, recién comienza a ser visibilizada en el trabajo formal, entonces ni que decir de los trabajadores informales que siguen por fuera del sistema de seguridad y salud en el trabajo, y que representan un poco más del 50 por ciento de la población trabajadora de Colombia.

Pero lo más grave de todo, es que el $56 \%$ de las y los trabajadores colombianos en general están excluidos del sistema de protección social en seguridad y salud laboral. Entre trabajadores independientes, en su mayoría vinculados a la economía informal, la cobertura es mucho menor. Solo el $4 \%$ de los independientes tienen acceso al sistema de seguridad social (Escuela Nacional Sindical, 2016, p.2).

En constrasste, como señalan en la Escuela Nacional Sindical (2016), hay algunos sectores en los que la desprotección es mucho mayor, y dan como ejemplo a las trabajadoras domésticas y a los trabajadores del campo, de los cuales solo están afiliados a las Administradoras de Riesgos Laborales el 3.4\% del total de la población que se encuentra afiliada al sistema laboral de Colombia.

Citación del artículo: Gómez, M., Calderón, P. (2017). Salud mental en el trabajo: entre el sufrimiento en el trabajo y la organización saludable. Revista Katharsis, N 23, enero-julio 2017, pp.177-201, Disponible en http://revistas.iue.edu.co/index.php/katharsis 
El Ministerio del trabajo, citado por Dinero.com (2014), informa que entre los resultados obtenidos a partir de la Segunda Encuesta de Seguridad y Salud en el Trabajo en Colombia, se identificó que las situaciones que mayor estrés generan en los trabajadores con consecuencias psicológicas, físicas y sociales negativas, son: 1) el trabajo excesivamente exigente; b) falta de tiempo para completar las tareas; c) falta de claridad sobre la función del trabajador; d) desajustes entre las exigencias del trabajo y la competencia del trabajador; e) falta de influencia en el modo en que se lleva a cabo el trabajo de cara al público y a clientes, y/o la exposición a la violencia de un tercero, del que recibe agresiones verbales; f) falta de apoyo de la dirección y los compañeros, g) acoso psicosocial en el lugar de trabajo; h) distribución injusta del trabajo, recompensas y ascensos; i) comunicación ineficaz; j) cambio organizativo mal gestionado. El estudio mostró que entre el 2009 y 2012, se presentó un incremento del $43 \%$ de la ansiedad y depresión como eventos procedentes de estos riesgos.

Al respecto de los trastornos mentales y de comportamiento, Mintrabajo y OISS (2013) señalan que en los resultados de la Segunda Encuesta Nacional de Condiciones de Seguridad y Salud en el Trabajo en Colombia "se observó un incremento del 43\% entre 2009 y 2012, principalmente por el reconocimiento de eventos de ansiedad y depresión (p.115) y agregan, que tuvo poca representatividad el diagnóstico del estrés, dado que este es más una consecuencia que conlleva la existencia de otros trastornos no únicamente mentales sino, además, físicos, tales como los cardiovasculares o los gastrointestinales.

En el Ministerio del Trabajo (2014a), reconocen que la naturaleza del trabajo va cambiando rápidamente ante las transformaciones que se van generando en la tecnología utilizada en los procesos productivos, los que, a su vez, modifican la diversidad de condiciones en el trabajo, y en el surgimiento de nuevas formas de realizar las tareas, las que, además, están enfocadas en el logro de estándares de calidad a un menor tiempo y con menos personal. Es así que estás condiciones llevan a un estado de presión y exigencias que afectan la salud, donde el estrés es registrado como el primer causante de alteraciones a la misma, traduciéndose en incapacidades repetidas y enfermedades laborales.

Con relación a los factores de riesgo psicosocial laboral cabe señalar que, con la actual legislación relativa al escenario laboral en Colombia, se expresa un mayor interés por mejorar la salud en el trabajo, ahora se cuenta con una concepción de salud que incluye lo psicosocial. En Colombia, con la ley 1010 de 2006 de acoso laboral; la resolución 2646 de 2008, sobre factores de riesgo psicosocial laboral; la resolución 652 del 2012, para la conformación de los comités de convivencia laboral; la ley 1562 de 2012, que modifica conceptos claves en la perspectiva de la salud en el trabajo, tales como los conceptos de accidente y enfermedad laboral, en la que presentan algunos diagnósticos psicológicos como una consecuencia de las condiciones de trabajo; y el decreto 1443 del 2014, que establece disposiciones para la implementación del Sistema de Gestión de la Seguridad y Salud en el Trabajo, como un sistema de cumplimiento y mejoramiento continuado; se viene configurando un escenario legal para impulsar un cambio de concepción por la vía de la obligación, y que da una base para que se pase de la coacción a la convicción con ayuda de la pedagogía. Es decir, que además de la legislación, se requiere de forma apremiante campañas pedagógicas que posibiliten que la norma pase de ser un medio de sanción a uno

Citación del artículo: Gómez, M., Calderón, P. (2017). Salud mental en el trabajo: entre el sufrimiento en el trabajo y la organización saludable. Revista Katharsis, N 23, enero-julio 2017, pp.177-201, Disponible en http://revistas.iue.edu.co/index.php/katharsis 
de autocuidado, protección y prevención, uno que comprenda de forma más duradera las prácticas sociales e individuales cotidianas.

En la Ley 1616 de 2013 de Colombia, la salud mental es vista como un estado que se expresa en la cotidianidad a través de la interacción, y que permite a las personas hacer uso de sus recursos emocionales, cognitivos y mentales para construir su vida diaria. Además, declara que la salud mental "es de interés y prioridad nacional para la República de Colombia, es un derecho fundamental, es tema prioritario de salud pública, es un bien de interés público y es componente esencial del bienestar general" (Art. 3).

El Ministerio del Trabajo desde 2008, en la Resolución 2646 planteó unos lineamientos para lograr la identificación, evaluación e intervención de factores de riesgo psicosocial, además de poder establecer el origen de las patologías que causan el estrés ocupacional. Cabe señalar que con la Ley 1616 del 2013 se logra fortalecer la concepción de salud mental, adicional que señala a las administradoras de riesgos laborales (ARL) como quienes lideraran en conjunto con sus empresas afiliadas la garantía de monitorear de forma constante los factores de riesgos psicosocial en el trabajo, a través del Sistema de Gestión de Seguridad y Salud en el Trabajo (SG-SST) (Ley 1616, 2013, Art. 9).

El Sistema General de Riesgos Laborales, tiene como propósito prevenir, proteger y atender a los trabajadores frente a las contingencias generadas por las enfermedades laborales y los accidentes de trabajo, que ocurran con ocasión o como consecuencia del trabajo que desarrolla la población laboral colombiana. A mayo de 2013, se cuenta con 10 ARL. La distribución de la afiliación en cuanto a trabajadores se divide en $63,31 \%$ a ARL privadas y $36,69 \%$ a ARL Positiva, que es pública. En cuanto a las empresas, el 22,19\% están asociadas a las ARL privadas y el $77,81 \%$ a la ARL Positiva (Ceballos, 2013, citada por Mintrabajo, 2013, párr. 6).

Actualmente en el país no contamos con mayores estudios que permitan determinar cuál es la carga de la patología mental en la productividad laboral, pero si podemos acercamos con presunciones construidas con algunas encuestas aisladas que permiten orientar las acciones en el ámbito laboral para dar importancia al abordaje de la salud laboral:

BOGOTÁ, oct. 30/15.- Según los resultados de una de las encuestas nacionales de condiciones de salud y trabajo, revelados por el Ministerio del Trabajo, dos de cada tres trabajadores manifestaron estar expuestos a factores psicosociales en su jornada laboral y entre un 20 por ciento y un 33 por ciento sintieron altos niveles de estrés.

La encuesta también evidencia que los riesgos ergonómicos y psicosociales son identificados como prioritarios. Un 14 por ciento de los encuestados expresó que no tiene tiempo para realizar sus tareas y el 43 por ciento se quejó de que debe realizar su trabajo de forma muy rápida o con plazos muy estrictos (Mintrabajo, 2015, párr. 1).

En Colombia, el Ministerio de Trabajo (2014b), define los factores de riesgo psicosocial como "aquellas condiciones del trabajo, del entorno o del individuo, que en una interrelación dinámica generan percepciones y experiencias, que influyen negativamente en la salud y en el desempeño de las personas" (p.13).

Citación del artículo: Gómez, M., Calderón, P. (2017). Salud mental en el trabajo: entre el sufrimiento en el trabajo y la organización saludable. Revista Katharsis, N 23, enero-julio 2017, pp.177-201, Disponible en http://revistas.iue.edu.co/index.php/katharsis 
En la tabla 2 y 3 se presentan los factores de riesgo ocupacional y las enfermedades que causan. Tomado del Decreto 1477 de 2014 de Colombia.

Tabla 2.

Agentes, factores de riesgo y enfermedades laborales.

Agentes etiológicos y factores de riesgo ocupacional Enfermedades

Gestión organizacional: (Deficiencias en la administración del recurso humano, que incluyen el estilo de mando, las modalidades de pago y de contratación, la participación, el acceso a actividades de inducción y capacitación, los servicios de bienestar social, los mecanismos de evaluación del desempeño y las estrategias para el manejo de los cambios que afecten a las personas, entre otros).

Características de la organización del trabajo: (Deficiencia en las formas de comunicación, la tecnología, la modalidad de organización del trabajo y las demandas cualitativas y cuantitativas de la labor).

Características del grupo social de trabajo: (Deficiencia en el clima de relaciones, cohesión y calidad de las interacciones, así como el trabajo en equipo, acoso psicológico).

Condiciones de la tarea: (Demandas de carga mental (velocidad, Complejidad, atención, minuciosidad, variedad y apremio de tiempo); el contenido mismo de la tarea que se define a través del nivel de responsabilidad directo (por bienes, por la seguridad de otros, por información confidencial, por vida y salud de otros, por dirección y por resultados); las demandas emocionales (por atención de clientes); especificación de los sistemas de control y definición de roles.

Carga física: (Esfuerzo fisiológico que demanda la ocupación, generalmente en términos de postura corporal, fuerza, movimiento y traslado de cargas e implica el uso de los componentes del sistema osteomuscular, cardiovascular y metabólico.

Condiciones del medioambiente de trabajo: (Deficiencia en: aspectos físicos (temperatura, ruido, iluminación, ventilación, vibración); químicos; biológicos; de diseño del puesto y de saneamiento, como agravantes o coadyuvantes de factores psicosociales.

Nota: adaptado y tomado de la Resolución 1443 de 2014 sobre Tabla de enfermedades laborales en Colombia. (p. 26 y 27).

Tabla 3.

Agentes, factores de riesgo y enfermedades laborales. Continuación. Agentes etiológicos y factores de riesgo ocupacional Enfermedades

Interfase persona-tarea: Evaluar la pertinencia del conocimiento y Gastritis crónica; no habilidades que tiene la persona en relación con las demandas de la especificada; Dispepsia; tarea, los niveles de iniciativa y autonomía que le son permitidos y el Síndrome del colon Citación del artículo: Gómez, M., Calderón, P. (2017). Salud mental en el trabajo: entre el sufrimiento en el trabajo y la organización saludable. Revista Katharsis, N 23, enero-julio 2017, pp.177-201, Disponible en http://revistas.iue.edu.co/index.php/katharsis 
reconocimiento, así como la identificación de la persona con la tarea y con la organización.

Jornada de trabajo: (Horarios y jornadas laborales extenuantes).

Deficiencia sobre la organización y duración de la jornada laboral; existencia o ausencia de pausas durante la jornada, diferentes al tiempo para las comidas; trabajo nocturno, trabajo por turnos; tipo y frecuencia de rotación de los turnos; número. y frecuencia de las horas extras mensuales y duración y frecuencia de los descansos semanales.

Accidentes de trabajo severos (amputaciones y atrapamientos, quemaduras, descargas eléctricas de alta tensión, accidentes de tránsito, caídas de gran altura, explosiones, ahogamientos y otros); asaltos, agresiones/ataque a la integridad física/violaciones.

Nota: adaptado y tomado del Decreto 1477 de 2014 sobre Tabla de enfermedades laborales en Colombia. (p. 28)

Actualmente se encuentra en borrador un Decreto sobre la Salud Mental en el trabajo (Ministerio del Trabajo, 2016), el cual tiene por objeto reglamentar la promoción de la salud mental y la prevención de problemas y trastornos mentales en el ámbito laboral.

\section{El sufrimiento en el trabajo desde una perspectiva psicodinámica.}

El trabajo es una actividad que exige contar con unas capacidades técnicas y una movilización de la subjetividad, es así como el trabajo se constituye en una fuente de identidad tanto para el individuo como para la colectividad, dado que se asumen roles y se llegan a acuerdos sobre las interpretaciones que se hacen de los estilos personales en el trabajo (Ansoleaga Moreno et al., 2014, p. A40).

Pin Arboledas (2013) considera que las organizaciones no tienen presentes conceptos como la responsabilidad social corporativa ni el equilibrio entre la vida laboral y la personal, sino que se orientan fundamentalmente a la rentabilidad, para la cual exigen una mayor productividad de su personal. De igual forma, enfatiza que esa búsqueda de rentabilidad, lleva a las organizaciones a "la reducción de personal, la bajada de sueldos y salarios, la disminución de la jornada o conceptos parecidos (p.5), para lograr una mayor reducción de costes, pero " [...] con estas medidas los empleados pierden la moral y se alejan del proyecto de empresa. Aunque permanezcan en ella, no saben cuánto tiempo tardarán en dejarla y se desidentifican con la compañía" (p.5), y aunque se queden en la organización, señala que, "a la larga su rendimiento baja. El trabajador piensa que la empresa no cuida de él y él, a su vez, no cuida de la empresa" (p.5). De allí la importancia de buscar equilibrios y un mejor relacionamiento entre la organización y quienes trabajan para y en ella.

Fleury \& Macêdo (2012), explican que la propuesta de la psicodinámica y clínica del trabajo surge con el propósito de estudiar la relación entre el hombre y el trabajo y que fue introducida por Christophe Dejours, quien se enfoca en abordar la génesis y las alteraciones del sufrimiento vinculadas a la organización del trabajo. La que sería fuente generadora de tensiones y malestares, con capacidad de desestructurar la vida psíquica del sujeto.

Citación del artículo: Gómez, M., Calderón, P. (2017). Salud mental en el trabajo: entre el sufrimiento en el trabajo y la organización saludable. Revista Katharsis, N 23, enero-julio 2017, pp.177-201, Disponible en http://revistas.iue.edu.co/index.php/katharsis 
La perspectiva de la Psicodinámica del Trabajo supone la incorporación de aspectos subjetivos del trabajo y se asume que el trabajo juega un rol protagónico en la constitución del individuo y de su identidad: el trabajar es más que una actividad, constituye una forma de relación social (Ansoleaga Moreno et al., 2014, p. A40)

Para Dejours (2015), cuando se habla de sufrimiento en relación al trabajo, enfatiza que no tiene mucho sentido separar el plano individual del colectivo, porque, tanto el uno, como el otro, hacen parte del vínculo subjetivo que se establece con el trabajo. Agrega que es habitual, en los momentos actuales, que se considere al trabajo como una desgracia originada socialmente, por la evolución del mundo del trabajo, y se refiere fundamentalmente al mundo occidental, en el que se da un aumento de patologías mentales asociadas al trabajo. Este aumento, explica, se da por la fragilización que es producida por:

[...] métodos de organización del trabajo que destruye los vínculos que se establecen entre las personas y que en lugar de la confianza, de la lealtad y de la solidaridad instalan en el mundo del trabajo el "sálvese quien pueda", la deslealtad, y finalmente una soledad implacable [...] (p.10).

Dejours (2015) argumenta que la introducción de técnicas como la evaluación individual del rendimiento, la "calidad total" y la precarización del empleo, han contribuido de forma importante al deterioro de la salud mental en el trabajo. Y de igual manera, enfatiza, que más allá de las patologías hay que "hacerle un lugar específico al análisis del sufrimiento" (p. $11)$.

Trabajar implica, además de poder utilizar la inteligencia, la capacidad de soportar de forma afectiva "[...] el fracaso que la realidad opone a la voluntad, al saber hacer y al dominio del proceso técnico (Dejours, 2009, p. 20). Dejours agrega que: "[...] la inteligencia en el trabajo solamente es eficiente si se acompaña de una obstinación y tenacidad que no flanquean ante los intentos infructuosos, los callejones sin salida y los fracasos de todo tipo que forman parte del trabajo cotidiano" (p.20). Es así que la persistencia en tolerar los fracasos y frustraciones se torna en una característica deseada por las organizaciones en el actual contexto pero que a la larga desgasta y fragiliza la relación con el trabajo.

Para este autor, en el más allá del trabajo, se da una resistencia en el mundo que afecta a las personas hasta en sus espacios domésticos, y se expresa en una afectación en su estado de ánimo, irritabilidad, preocupaciones, insomnio, indisponibilidad afectiva, etc.

El trabajo no sólo produce aquello que tenemos de mejor o de peor a nivel individual. Puede también generar aquello que hay de mejor a nivel colectivo, o sea, la armonía y el "vivre-ensemble" "[1] así como lo peor, o sea, la soledad - y hasta la desolación -, la desconfianza, el miedo y la instrumentalización de los seres humanos, llegando al extremo de llevar a algunos de nosotros a quitar sus vidas frente a los propios colegas" (Dejours, 2011, p. 15).

Para Dejours \& Gernet (2014) si bien es muy frecuente escuchar diariamente el uso de términos como "estrés", "malestar" o "sufrimiento", opinan que se hace necesario diferenciarlos dado que poseen elementos particulares que posibilitan entender "[...] la identificación del origen de los trastornos observados, pero también sobre las concepciones de la acción, de la prevención y de las elecciones en términos de políticas de salud en el trabajo" (p.23). Citación del artículo: Gómez, M., Calderón, P. (2017). Salud mental en el trabajo: entre el sufrimiento en el trabajo y la organización saludable. Revista Katharsis, N 23, enero-julio 2017, pp.177-201, Disponible en http://revistas.iue.edu.co/index.php/katharsis 
Es así que se toman los términos de "estrés" y "sufrimiento" y plantean que el estrés ha sido identificado como la consecuencia de un "desequilibrio entre las capacidades de respuesta efectivas proporcionadas por un individuo frente a situaciones provenientes del entrono (afectivo y profesional)" (p. 23). Es así que se trata que sea el individuo el que se adapte a las exigencias del mundo para hacerle frente a las situaciones problemáticas que se le presentan. Dejours \& Gernet (2014) muestran que los modelos del estrés se enfocan en "intervenciones focalizadas en la búsqueda de factores predictivos del estrés y de factores de protección de la salud en el trabajo, desde el punto de vista de la organización (p.23).

Con relación al "sufrimiento" Dejours \& Gernet (2014), toman referentes de la psicopatología general, del psicoanálisis y de la psicosomática, para situar al "sufrimiento" como un concepto que da cuenta de un padecer particular que refleja la vida psíquica. Y advierten que si bien "puede ser objeto de un consenso entre los médicos clínicos, también suscita discusiones en el campo de las ciencias humanas, en particular por el riesgo de "psicologización" de los fenómenos sociales que podría ocasionar" (Ehrenberg y Douville, 2014, citados por Dejours y Gernet, 2014). Explican que el sufrimiento, como vivencia subjetiva, implica una experiencia particular que se vincula con situaciones y prácticas de trabajo concretas.

Para Dejours \& Gernet (2014) el concepto de sufrimiento posibilita identificar la variedad de procesos psíquicos que se movilizan en las diversas situaciones producidas en el escenario de trabajo, y permite analizar el vínculo subjetivo que se crea frente a los contenidos específicos del trabajo, tales como: el aburrimiento y la monotonía; el miedo; y la confrontación con la injusticia y el sufrimiento ético.

En la revisión de los aportes que hace Dejours (2009, 2010, 2011 y 2015) para comprender la complejidad de la relación actual al trabajo, se construye la figura 1. El trabajo actual y el sufrimiento, en la que se plantean ideas centrales de la visión psicodinámica del trabajo.

Citación del artículo: Gómez, M., Calderón, P. (2017). Salud mental en el trabajo: entre el sufrimiento en el trabajo y la organización saludable. Revista Katharsis, N 23, enero-julio 2017, pp.177-201, Disponible en http://revistas.iue.edu.co/index.php/katharsis 


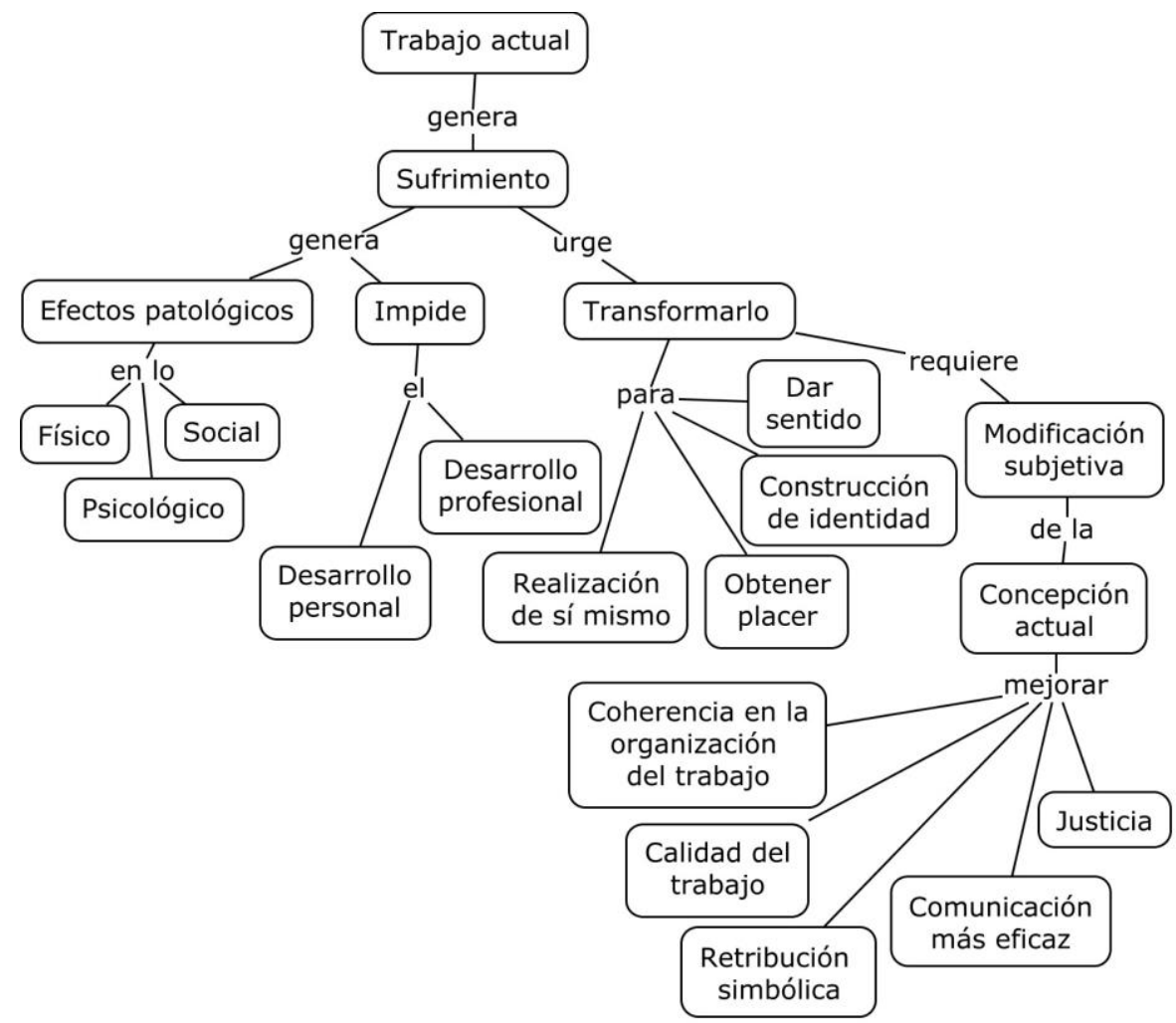

Figura 2. El trabajo actual y el sufrimiento. Construcción a partir de la revisión de Dejours (2009, 2010, 2011 y 2015) y Dejours y Gernet (2014).

\section{Sobre las organizaciones saludables y la búsqueda de bienestar}

El desarrollo de organizaciones saludables es un concepto que se ha generado durante el siglo XX (Gimeno, 2012) aunque al momento no se sabe la forma de crearlas, requiere hacerse "necesariamente, desde una aproximación multinivel" (p. 60), que, además, incluya los análisis de los puestos de trabajo así como el de la organización. Para Gimeno (2012) el mundo actual vive momentos de tensión y de cambio de la concepción de salud en las organizaciones porque, adicionalmente, el mundo organizativo requiere enfocarse en la protección y promoción de la salud.

Para el Departamento de Seguridad, Salud y Nuevos Servicios de Mutua Navarra (2008), el hecho de que las organizaciones acepten el fomento de la salud en el trabajo para lograr ambientes saludables muestra un paso básico para la sociedad y va más allá de considerar que las condiciones de trabajo pueden producir lesiones y daños, sino que promover hábitos saludables que aportan a las personas y la sociedad permite mejorar la imagen de las organizaciones.

El bienestar de las personas es, por consiguiente, un activo intangible que las empresas vienen utilizando cada vez con más frecuencia para conseguir reputación, notoriedad o simplemente un incremento de ventas. Así, la salud se ha convertido en un valor transversal que traspasa las fronteras del mercado asociado tradicionalmente al monetarismo para convertirse en elemento

Citación del artículo: Gómez, M., Calderón, P. (2017). Salud mental en el trabajo: entre el sufrimiento en el trabajo y la organización saludable. Revista Katharsis, N 23, enero-julio 2017, pp.177-201, Disponible en http://revistas.iue.edu.co/index.php/katharsis 
diferenciador que refuerza su imagen de responsabilidad y abre así nuevos mercados (p.9).

Para Salanova (2009) una de las principales razones que trae una organización saludable consiste en que sus beneficios económicos y sociales son mucho mayores a las organizaciones consideradas tóxicas. Esta autora señala que es importante dejar de ver la salud de los trabajadores como un medio y lograr verla como una finalidad que aporta de forma constructiva a la organización, por lo que se constituye en un valor estratégico.

Las organizaciones saludables, insiste Carrión (2012), son las que consideran la calidad como un condición clave a desarrollar en todos los ámbitos de la actividad organizacional, y dichas organizaciones se diferencian de las otras, por tener una gestión activa en la promoción de la salud de las personas que trabajan, considerando el bienestar físico, mental y social en el más alto nivel, porque entienden que "la exposición continuada a factores psicosociales nocivos en el ámbito laboral puede provocar daños a la salud de los trabajadores aun cuando no se manifiesten de forma inmediata" (p.1).

Para Parra (2001) el trabajo es una actividad humana y un fenómeno colectivo en el que las personas con intereses similares buscan agruparse, y uno de sus intereses es la búsqueda del bienestar psicológico que mueve a trabajadores para desarrollar acciones en conjunto. "El trabajo en la actualidad es una realidad compleja y heterogénea, [...] cuyo elemento en común es estar orientado por la lógica de desarrollo de la sociedad capitalista, que plantea la convergencia de individuos movidos por necesidades económicas [...]” (p.4).

Wilson et al., citado por Salanova (s.f.), definen a las organizaciones saludables como:

[...] aquellas organizaciones caracterizadas por invertir esfuerzos de colaboración, sistemáticos e intencionales para maximizar el bienestar de los empleados y la productividad, mediante la generación de puestos bien diseñados y significativos, de ambientes sociales de apoyo, y finalmente mediante las oportunidades equitativas y accesibles para el desarrollo de la carrera y del balance trabajo-vida privada". (p. 9).

Salanova (2008) explica que las organizaciones modernas esperan que sus empleados tengan iniciativa y sean proactivos, se ausenten poco, sean colaboradores, responsables de su propio desarrollo de carrera, y que se comprometan con la excelencia de la empresa, pero señala la autora, este objetivo organizacional no puede lograrse si los empleados no están satisfechos con sus trabajos y experimentan estrés laboral, advierte que con la forma tradicional de dirigir las organizaciones, no se lo logrará, y que se necesita algo más para poner en marcha en la organización.

Salanova (s.f.) señala que la organización hace referencia a los estilos en que se estructuran y gestionan los procesos de trabajo, incluyendo el diseño de los puestos, los horarios de trabajo, la manera de dirección, la efectividad organizacional y las estrategias organizacionales para la adaptación de los empleados, esto es, las prácticas de desarrollo de los recursos humanos. El complemento de la palabra saludable deriva de la idea de que es posible distinguir sistemas de organizaciones sanos y enfermos. Distinguir, finalmente, formas de estructurar y gestionar los procesos de trabajo con resultados más saludables que otros, es crear y mantener organizaciones sanas para todos, esto es, empleados, empleadores, clientes - usuarios y para la sociedad en general.

Citación del artículo: Gómez, M., Calderón, P. (2017). Salud mental en el trabajo: entre el sufrimiento en el trabajo y la organización saludable. Revista Katharsis, N 23, enero-julio 2017, pp.177-201, Disponible en http://revistas.iue.edu.co/index.php/katharsis 
Para Newell (2003), las organizaciones hoy no pueden seguir descuidando a su "talento humano" si quieren ser competitivas, porque para lograr sus resultados tienen que promover el bienestar positivo de las personas, agrupaciones y sociedades, para que sean más eficaces y comprometidos.

El modo tradicional de aumentar la competitividad era reducir los costes, y eso se lograba reduciendo los gastos generales. [...] Lo irónico es que esto se ha hecho muchas veces sacrificando la calidad, la flexibilidad y la innovación, y pasando por alto el impacto sobre el medio ambiente, los empleados o la comunidad en general. La calidad, la flexibilidad, la innovación y la responsabilidad organizacional solo se consiguen mediante el compromiso y la cooperación de los empleados (p.2).

Describe Salanova (s.f.) que la esencia de un great place to work, es un lugar donde los empleados confían en la gente con la que trabajan, disfrutan de las personas con las que trabajan y confían en lo que hacen. La autora explica que esto se da porque ocurre a través de tres tipos de relaciones interconectadas: 1) buenas relaciones entre los empleados y la dirección; b) buenas relaciones interpersonales entre empleados; y c) buenas relaciones y adaptación entre los empleados y su propio trabajo/empresa.

Para Newell (2003), hoy una organización sana, es aquella que facilita las oportunidades de satisfacción de las necesidades de los trabajadores, y de esta forma, también logra beneficiarse de una mayor contribución de los mismos. "El éxito depende cada vez más del empleo de la flexibilidad y creatividad exclusivas de la mente humana para controlar un clima turbulento por momentos y responder a él" (p.36).

Es así, entonces, como podría concluirse que, serían organizaciones más saludables, entendiendo la salud no como la ausencia de enfermedad o problemas, sino como el estado de bienestar físico, social, psicológico y, por supuesto, con un bienestar económico.

Cabe precisar que el enfoque teórico sobre el cual el concepto organizaciones saludables se diferencia del generado en el marco del estrés ocupacional, es decir, desde una perspectiva más positiva, donde se pueden estudiar las organizaciones saludables optimizando el capital humano, el capital social y el así llamado capital psicológico, a la vez que se maximiza la estrategia de la organización o empresa (Salanova, s.f.).

En dicho contexto los modelos de gestión tradicionales que consideran a los empleados como instrumentos para conseguir los fines empresariales, están siendo reemplazados por una Psicología Ocupacional u Organización Positiva (PoP), que considera la salud del empleado como una meta en sí misma y un objetivo legítimo que debe incluirse en las políticas organizacionales. La Psicología Positiva fue definida como el estudio científico del funcionamiento humano óptimo (Seligman, 1999). En el ámbito del trabajo y de las organizaciones, la Psicología Ocupacional u Organización Positiva - PoP, se ha definido como el estudio científico del funcionamiento óptimo de las personas y de los grupos en las organizaciones, así como en su gestión efectiva.

Se entiende que de alguna manera, las formas positivas de estructurar y gestionar los procesos de trabajo en las organizaciones son 'saludables' en la medida que las personas que trabajan en ellas son también 'saludables', y la organización tiene servicios y/o productos excelentes y, a su vez, buenas relaciones con el entorno social y comunitario.

Citación del artículo: Gómez, M., Calderón, P. (2017). Salud mental en el trabajo: entre el sufrimiento en el trabajo y la organización saludable. Revista Katharsis, N 23, enero-julio 2017, pp.177-201, Disponible en http://revistas.iue.edu.co/index.php/katharsis 
Warr (1990, citado por Salanova, s.f), ha identificado hasta nueve características o recursos del trabajo que afectan al bienestar psicológico: (1) la claridad de las tareas y del rol laboral, (2) la autonomía en el trabajo, (3) las oportunidades que ofrece el trabajo para el contacto social, (4) la variedad de las tareas, (5) la existencia de información y feedback sobre el trabajo, (6) un salario justo, (7) la seguridad física en el trabajo, (8) que el trabajo sea valorado socialmente, y (9) el apoyo del supervisor.

Con relación al concepto "saludable" dado a las organizaciones, Salanova (s.f.) propone entenderlo como una nueva forma en el cuidado de la salud de la organización. Lo cual también indica una nueva dirección en el desarrollo de los recursos humanos, con la posibilidad de ver la salud psicológica y social como una vía para conseguir otros fines más psicosociales respondiendo, a su vez, a valores estratégicos de la empresa.

Para la psicología Organizacional Positiva, el capital psicológico positivo se inicia desde las fortalezas personales y capacidades psicológicas que pueden ser medidas, desarrolladas y gestionadas con la finalidad de obtener un desempeño mejor en las organizaciones actuales. Según datos que arrojan la investigación al respecto se ha identificado que estas características básicas son: la autoeficacia, la esperanza, el optimismo y la resiliencia (Luthans, Youssef \& Stanjovik, 2004, citados por Salanova, s.f). Este capital psicológico positivo tiene efectos beneficiosos tanto para la persona, ya que contribuye a su bienestar y facilitan el desarrollo de habilidades, como para el grupo y la organización ya que finalmente se podría hablar de un capital psicosocial compartido entre los miembros de las organizaciones saludables.

Cabe traer una descripción que señala Salanova (s.f), donde presenta un modelo heurístico de organización saludable (figura 3) entendida como aquella que desarrolla (1) prácticas saludables para estructurar y gestionar los procesos de trabajo que influirían en el desarrollo de (2) empleados saludables y (3) resultados organizacionales saludables. Estas dimensiones están relacionadas entre sí, y esta interdependencia influye en el desarrollo de empleados y resultados organizacionales, que a su vez influirían en el mejoramiento de las formas de planear y organizar los procesos de trabajo.

Citación del artículo: Gómez, M., Calderón, P. (2017). Salud mental en el trabajo: entre el sufrimiento en el trabajo y la organización saludable. Revista Katharsis, N 23, enero-julio 2017, pp.177-201, Disponible en $\mathrm{http}: / /$ revistas.iue.edu.co/index.php/katharsis 


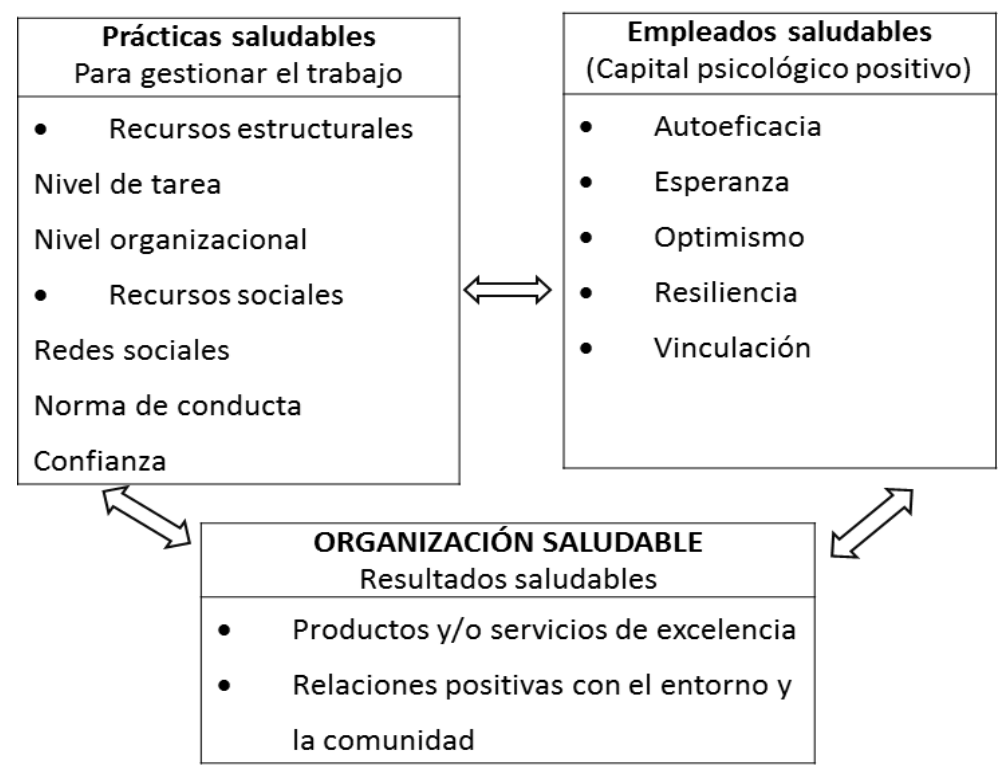

Figura 3. Modelo heurístico de organización saludable (Salanova, s.f., p. 32.).

Hay un aspecto importante (Salanova, s.f.) el cual indica que el estado de vinculación psicológica con el trabajo se ajusta a los resultados que se obtienen con el desempeño, el bienestar y la calidad de vida en general, como si se tratara de un estado positivo que hace posible y facilita el uso de recursos. Desde la perspectiva organizacional, la vinculación con el trabajo se relaciona positivamente con el desempeño y la fidelidad del cliente, el desempeño académico en estudiantes universitarios y el compromiso organizacional, el desempeño en equipos y negativamente con el absentismo, rotación y tendencia al abandono (p.10).

El aumento en el bienestar psicosocial facilita la adaptación a cualquier situación de adversidad, además, supone un incremento de la confianza en sí mismo, dando lugar a las espirales positivas; este capital psicológico positivo tiene, pues, efectos beneficiosos tanto para la persona, porque aporta a su bienestar y proporciona el proceso de adquisición de habilidades, a nivel del grupo y la organización, podríamos decir que es un capital psicosocial compartido entre los miembros de las organizaciones saludables.

¿Existen entonces las organizaciones saludables? Esta pregunta aplicada al contexto de nuestro país Colombia nos pone a pensar, pues se ha venido trabajando en ello en los últimos años, al menos desde la academia se evidencia mayor ocupación en el tema, sin embargo, podemos decir que es incipiente su aparición y la forma en que se estructura el concepto en la realidad de las organizaciones, puesto que, quienes como institución avalan o certifican lo hacen con un modelo de organización saludable, según un enfoque que a nuestro modo de ver es oportuno, sigue siendo más centrado en lo biológico, y amerita complementarse de forma más integral con un enfoque más contundente que dé cuenta de un abordaje más psicosocial.

A modo de cierre, es importante señalar que hay buscar formas novedosas e interdisciplinarias para construir diariamente organizaciones que sean más saludables y que,

Citación del artículo: Gómez, M., Calderón, P. (2017). Salud mental en el trabajo: entre el sufrimiento en el trabajo y la organización saludable. Revista Katharsis, N 23, enero-julio 2017, pp.177-201, Disponible en http://revistas.iue.edu.co/index.php/katharsis 
además, de enfocarse en unos objetivos organizacionales, integren los objetivos individuales y sociales a su gestión, presente y futura.

\section{Conclusiones}

- La salud mental y bienestar en el contexto laboral pueden ser entendidos como un proceso dialéctico del comportamiento humano individual y colectivo, al ser una práctica social, que se basa y representa la capacidad de transformación de la realidad en el proceso de producción, a través del sistema socioeconómico predominante.

- En Colombia se cuenta con una legislación que busca propiciar condiciones de trabajo más idóneas, en las que el autocuidado, la prevención, promoción de la salud, y la asistencia psicosocial laboral estén más presentes en la cotidianidad de las organizaciones, y que está en camino de aplicación.

- En el ámbito laboral se requiere más pedagogía y reconocimiento de las relaciones de interdependencia que se dan entre trabajadores, organizaciones y Estado, actores fundamentes de la sociedad para el alcance del bienestar.

- El sufrimiento en el trabajo, desde una perspectiva psicodinámica, posibilita identificar la variedad de procesos psíquicos que se movilizan en las diversas situaciones producidas en el escenario de trabajo, y permite analizar el vínculo subjetivo que se crea frente a los contenidos específicos del trabajo, tales como: el aburrimiento y la monotonía; el miedo; y la confrontación con la injusticia y el sufrimiento ético.

- La concepción de organización saludable hace referencia al escenario de trabajo que posibilita las oportunidades para satisfacción de las necesidades de los trabajadores e, igualmente, de beneficiarse de la contribución de los mismos.

- De la psicología positiva ha surgido una aplicación denominada Psicología Ocupacional u Organización Positiva (PoP), que considera la salud del empleado como una meta en sí misma y como un objetivo legítimo que debe incluirse en todas las políticas organizacionales, para beneficio de los empleados y del mismo sistema organizacional.

\section{Referencias}

Acosta, M., Aldrete, M., Alvarado C., Aranda, C., Arellano, G., Bermúdez, R.,... Varillas, W. (2006). Factores psicosociales y salud mental en el trabajo. Universidad de Guadalajara, México. Recuperado de http://www.rialnetportal.org/documentos/rial/sso_peru/Documentos\%20aportados\%20 por $\% 201$ os $\% 20$ participantes/Factores $\% 20$ Psicosociales $\% 20 y \% 20$ Salud $\% 20$ Mental $\% 2$ 0en\%20el\%20Trabajo.pdf

Agencia Europea para la Seguridad y Salud en el trabajo. (2016). Los riesgos psicosociales y el estrés en el trabajo. Recuperado de https://osha.europa.eu/es/themes/psychosocialrisks-and-stress

Andrade, V., Gómez, I. C. (2008). Salud Laboral Investigaciones realizadas en Colombia. Pensamiento Psicológico, 4 (10) 9-25. Recuperado de http://revistas.javerianacali.edu.co/index.php/pensamientopsicologico/article/view/701/ 977

Citación del artículo: Gómez, M., Calderón, P. (2017). Salud mental en el trabajo: entre el sufrimiento en el trabajo y la organización saludable. Revista Katharsis, N 23, enero-julio 2017, pp.177-201, Disponible en $\mathrm{http}: / /$ revistas.iue.edu.co/index.php/katharsis 
Andrés, R., Bonal, S., Borges, I., Cuadrat, L., Fernández, A., Fernández, L., Ferrero, E., Haro, M., Hortet, J., Llorens, C., Luna, M., Martínez, S., Mateo, M., Medina, A., Moncada, S., Potenciano, L., Tejada, J. (2015). Guía para la intervención sindical en organización del trabajo y riesgos psicosociales. Recuperado DE http://www.istas.net/web/abreenlace.asp?idenlace=4891

Ansoleaga Moreno, E., Chenevard, C., Gómez Rubio, C., Luco González, C., Polywoda Sancha, X., Dávila Figueras, A. (2014) Clínica Psicosocial del Trabajo: Una Propuesta de Intervención. Ciencia \& Trabajo. 51, A39 - A45. Recuperado de http://www.cienciaytrabajo.cl/cyt/Paginas/Clinica-Psicosocial-del-Trabajo-Unapropuesta-de-intervencion.aspx

Banco Mundial. (2016). Salir de la penumbra: Hacer que la salud mental sea una prioridad de desarrollo a nivel mundial. Recuperado de http://envivo.bancomundial.org/hacerque-la-salud-mental-sea-una-prioridad-de-desarrollo-a-nivel-

mundial?cid=ECR_FB_worldbank_ES_SM16_EXTP

Barlow, J. (2000). Gestión del Estrés: Cómo vencer los obstáculos y mejorar la actitud y su calidad de vida. Barcelona: Gestión 2000.

Carrión, M. A. (2012). Organizaciones saludables en tiempo de crisis. Revista Colombiana de Salud Ocupacional, 2(1), pp 1-2. Recuperado de http://revistasojs.unilibrecali.edu.co/index.php/rcso/article/view/54/423

Dejours, Ch. (2009). Trabajo y Violencia. Madrid: Ed. Modus Laborandi.

Dejours, Ch. (2010). Contribución de la Clínica del Trabajo a la Teoría del Sufrimiento. Recuperado de https://www.topia.com.ar/articulos/contribuci\%C3\%B3nc1\%C3\%ADnica-del-trabajo-teor\%C3\%AD-del-sufrimiento

Dejours, Ch. (2011). Psicopatologia do trabalho - Psicodinâmica do Trabalho. Laboreal, 7 , (1), 13-16. Recuperado de http://laboreal.up.pt/files/articles/13_16f2_1.pdf

Dejours, Ch. (2015). El sufrimiento en el trabajo. Buenos Aires: Editorial Topia.

Dejours, Ch., Gernet, I. (2014). Psicopatología del trabajo. Buenos Aires: Miño y Davila.

Departamento de Seguridad, Salud y Nuevos Servicios de Mutua Navarra. (2008). Promoción de la salud en el trabajo. Una oportunidad empresarial. Navarra: Mutua Navarra.

Dinero.com. (Febrero 11 de 2014). Principales generadores de estrés laboral en Colombia. Recuperado de http://www.dinero.com/pais/articulo/causas-del-estres-laboralcolombia/202788

Fleury, A. y Macêdo, K. (2012). Límites y posibilidades del método en psicodinámica y clínica del trabajo: Relato de los estudios del grupo de la Pontificia Universidade Catolica de Goiás. PRAXIS. Revista de Psicología. 14 (21), 77-92. Recuperado de http://www.praxis.udp.cl/pdf/21/Praxis21-06.pdf

Elempleo. (24 de marzo de 2015). Estrés, un mal que aqueja el entorno laboral. Recuperado de http://www.elempleo.com/colombia/consejos_profesionales/estrnos-un-mal-queaqueja-el-entorno-laboral------/15453457

Escuela Nacional Sindical. (28 de abril de 2016). En Colombia, cifras que enferman y matan. Agencia de Información Laboral ENS.

Gómez, I. C. (2007). Salud laboral: una revisión a la luz de las nuevas condiciones del trabajo. Univ. Psychol. 6 (I): 105-113. Recuperado de http://pepsic.bvsalud.org/scielo.php?script=sci_arttext\&pid=S165792672007000100011

Citación del artículo: Gómez, M., Calderón, P. (2017). Salud mental en el trabajo: entre el sufrimiento en el trabajo y la organización saludable. Revista Katharsis, N 23, enero-julio 2017, pp.177-201, Disponible en http://revistas.iue.edu.co/index.php/katharsis 
Gimeno, M. A. (2012). El modelo emergente de la organización saludable: factores para su construcción y desarrollo evolutivo. Tesis doctoral. Universitat Jaume. Recuperado de http://www.tdx.cat/handle/10803/104157

Houtman; L.D., Kompier, M. (1998). Trabajo y salud mental. En Enciclopedia de salud y seguridad en el trabajo. Tercera edición. Madrid: Gestión editorial. Chantal Dufresne, BA Recuperado de http://www.insht.es/InshtWeb/Contenidos/Documentacion/TextosOnline/Enciclopedia OIT/tomo1/5.pdf

ISTAS (s.f.) Salud laboral. El Instituto Sindical de Trabajo, Ambiente y Salud. Recuperado de http://www.istas.net/web/index.asp?idpagina=1233

Martínez, E. (2016). Relaciones de intercambio en las organizaciones y riesgos psicosociales: un estudio sobre la relación del contrato psicológico y el burnout (desgaste ocupacional) en una muestra de empleados mexicanos. En: Uribe, J. F. (2016). Psicología del trabajo. Un entorno de factores psicosociales saludables para la productividad. México: Manual Moderno. Pp. 129 - 138

Ministerio de Salud y Protección Social. (2013). Ley 1616 de 2013, por medio de la cual se expide la ley de salud mental y se dictan otras disposiciones. Recuperado de http://wsp.presidencia.gov.co/Normativa/Leyes/Documents/2013/LEY\%201616\%20D EL\%2021\%20DE\%20ENERO\%20DE\%202013.pdf

Ministerio del Trabajo. (2014a). Protocolo para la determinación del origen de las patologías derivadas estrés. Recuperado de http://www.fasecolda.com/files/1714/4969/7289/Ministerio_del_Trabajo._2014._Proto colo_para_la_determinacin_del_origen_de_las_patologas_derivadas_del_estrs._3_Ed.. pdf

Ministerio del trabajo (2014b). Decreto 1477 de 2014. Tabla de enfermedades laborales. Recuperado file:///C:/Users/USUARIO/Downloads/decreto_1477_del_5_de_agosto_de_2014.pdf

Mintrabajo (2015). La salud mental de los trabajadores, prioridad del Ministerio del Trabajo. Recuperado de http://www.mintrabajo.gov.co/octubre-2015/4953-la-saludmental-de-los-trabajadores-prioridad-del-ministerio-del-trabajo-.pdf

Mintrabajo (2013). Panorama de la salud laboral en Colombia. Recuperado de http://www.mintrabajo.gov.co/medios-agosto-2013/2153-panorama-de-la-saludlaboral-en-colombia.html

Mintrabajo y OISS (2013). Segunda Encuesta Nacional de Condiciones de Seguridad y Salud en el Trabajo en Colombia. Recuperado de file:///E:/Riesgo\%20psicosocial\%20UPB/II_ENCUESTA_NACIONAL_CONDICION ES_SST_COLOMBIA_2013.pdf

Ministerio del Trabajo (2016). Proyecto de Decreto de Salud Mental. Documento Borrador. Recuperado de http://www.google.com.co/url? sa=t\&rct=j\&q=\&esrc=s\&source=web\&cd=1\&ved=0ah UKEwik18iOsMzQAhUGfpAKHRC-

DC8QFggYMAA\&url=http\%3A\%2F\%2Fwww.mintrabajo.gov.co\%2Fcomponent $\% 2$ Fdocman\%2Fdoc_download\%2F9866-proyecto-decreto-saludmentalpdf.html\&usg=AFQjCNGdflj1IkQK5n9FXUT16smer2JKvA\&bvm=bv.139782 $543, \mathrm{~d}$.Y2I

Citación del artículo: Gómez, M., Calderón, P. (2017). Salud mental en el trabajo: entre el sufrimiento en el trabajo y la organización saludable. Revista Katharsis, N 23, enero-julio 2017, pp.177-201, Disponible en http://revistas.iue.edu.co/index.php/katharsis 
Morales, E. (2016). Factores de riesgo psicológico en el trabajo. En: Uribe, J. F. (2016). Psicología del trabajo. Un entorno de factores psicosociales saludables para la productividad. México: Manual Moderno. Pp. 35- 64

Nava, R. (2016). Alteraciones en la salud en trabajadores que laboran rotando turnos y trabajo nocturno: el ciclo o ritmo circadiano. En: Uribe, J. F. (2016). Psicología del trabajo. Un entorno de factores psicosociales saludables para la productividad. México: Manual Moderno. Pp. 159- 168

Newell, S. (2003). Creando Organizaciones Saludables: Bienestar, ética y diversidad en el trabajo. México: Thomson.

Salud.com.ar (3 de agosto de 2015). Japón: diez mil muertes por estrés laboral. Recuperado de http://www.salud.com.ar/es/japon-diez-mil-muertes-por-estres-laboral.html

Salanova, M. (2008). Organizaciones saludables y desarrollo de recursos humanos. Estudios Financieros. 303, 179-214. Recuperado de https://dialnet.unirioja.es/servlet/articulo?codigo=2653399

Salanova, M. (s.f.). Organizaciones Saludables: Una aproximación desde la Psicología Positiva. Recuperado de http://www.integraorg.com/wpcontent/docs/organizaciones\%20saludables.pdf

Salanova, M. (2009). Organizaciones saludables, organizaciones Resilientes. Gestión Práctica de Riesgos Laborales, 58, 18-23. Recuperado de http://repositori.uji.es/xmlui/bitstream/handle/10234/73232/32403.pdf?sequence=1

Sánchez, P. (2006). Cambios a la normativa: Salud Mental y Trabajo: ¿Un Problema en Alza? Ciencia \& Trabajo. 8(21), 64-69. Disponible en http://www.proyectoaraucaria.cl/documentos/20080108094917Salud\%20Mental\%20y \%20Trabajo,\%20un\%20problema\%20en\%20alza.pdf

Seligman, M. E. P. (1999). The president's address. American Psychologist. 54, 559-562. Recuperado de http://dx.doi.org/10.1037/0003-066X.54.8.537

Steven L. Sauter, Joseph J. Hurrell Jr., Lawrence R. Murphy y Lennart Levi. (1998). Factores psicosociales y de organización. En Enciclopedia de salud y seguridad en el trabajo. Tercera edición. Madrid: Gestión editorial. Chantal Dufresne, BA. Recuperado de

http://www.insht.es/InshtWeb/Contenidos/Documentacion/TextosOnline/Enciclopedia OIT/tomo2/34.pdf

OIT (2000). ¡Auxilio estrés! Salud mental en el trabajo. Revista de la OIT. No 37, diciembre de 2000. Recuperado de http://www.ilo.org/wcmsp5/groups/public/---dgreports/--dcomm/documents/publication/dwcms_080699.pdf

OMS, (2016). Salud mental: fortalecer nuestra respuesta. Centro de Prensa. Recuperado de http://www.who.int/mediacentre/factsheets/fs220/es/

Parra, M. (2001). Monografías de Gestión en Psiquiatría y Salud Mental. Salud Mental y Trabajo. Universidad de Santiago. Recuperado de http://www.facso.uchile.cl/psicologia/epe/_documentos/salud_docente/manuel_parra_s alud_mental_trabajo.pdf

Pando, M.; Aranda, C.; Salazar, J. G., Bermúdez, D. (2006). La salud mental positiva. En Acosta Fernández et al. (2006). Factores psicosociales y salud mental en el trabajo. pp. 86-103, Universidad de Guadalajara, México. Recuperado de http://www.rialnetportal.org/documentos/rial/sso_peru/Documentos\%20aportados\%20

Citación del artículo: Gómez, M., Calderón, P. (2017). Salud mental en el trabajo: entre el sufrimiento en el trabajo y la organización saludable. Revista Katharsis, N 23, enero-julio 2017, pp.177-201, Disponible en http://revistas.iue.edu.co/index.php/katharsis 
por\%20los\%20participantes/Factores\%20Psicosociales\%20y\%20Salud\%20Mental\%2 0en\%20el\%20Trabajo.pdf

Pin Arboledas, J. R. (2013). Presentación. En: García Lombardía, P., Peiró Barra, A. Productividad y empresa saludable. Navarra: Centro Internacional de Investigaciones Organizacionales

Prieto Rodriguez, A. (2002). Salud Mental: Situación y Tendencias. Revista de Salud $\begin{array}{lllll}\text { Pública. } & 4 & \text { (1), } & \text { 74-88. } & \text { Recuperado de }\end{array}$ http://www.scielo.org.co/pdf/rsap/v4n1/v4n1a05.pdf

Torres, J. R. (2016). Calidad de vida. En: Uribe, J. F. (2016). Psicología del trabajo. Un entorno de factores psicosociales saludables para la productividad. México: Manual Moderno. Pp. 17- 26

Valerio, M. (15 de octubre de 2009). Crisis y estrés laboral, un cóctel mortífero. El mundo.es.

Recuperado

de http://www.elmundo.es/elmundosalud/2009/10/14/medicina/1255536616.html

Vásquez, C., Hervás, G. (2008). Salud mental positiva: del síntoma al bienestar. En Psicología Positiva aplicada. (pp. 17-39). Bilbao: Desclee de Brower. Recuperado de http://www.ucm.es/data/cont/docs/3-2013-02-18-8-

SALUD\%20MENTAL\%20POSITIVA.pdf

Villalobos, G. (2004). Vigilancia epidemiológica de los factores psicosociales. Aproximación conceptual y valorativa. Cienc Trab. 6(14):197-201. Recuperado de http://www.huila.gov.co/documentos/V/vigilancia_epidem_psicosociales.pdf

Citación del artículo: Gómez, M., Calderón, P. (2017). Salud mental en el trabajo: entre el sufrimiento en el trabajo y la organización saludable. Revista Katharsis, N 23, enero-julio 2017, pp.177-201, Disponible en http://revistas.iue.edu.co/index.php/katharsis 